\title{
因HAD
}

ISSN-L: 2530-5115

(c) (1) (-)

\section{Editorial: $1^{\circ}$ Congreso Mundial de Hospitalización a Domicilio}

\author{
Editorial: 1st World Congress of Hospital at Home
}

Correspondencia/Correspondence

Beatriz Massa Domínguez

massa_bea@gra.es

Recibido/Received

08.01 .2018

Aceptado/Accepted

13.01 .2019
Conflicto de Intereses/Competing interest

No existe ningún conflicto de interés en la presente declaración. 8. 


\section{$1{ }^{\circ}$ CONGRESO MUNDIAL DE HOSPITALIZACIÓN A DOMICILIO (HAD)}

A veces..., las cosas tanto en el plano personal como profesional surgen casi "sin avisar", y nos obligan a extremar la intuición para saber si el tren que pasa es el apropiado para nosotros y debemos subirnos, porque de otro modo la oportunidad se desvanecerá para siempre.

A veces..., las cosas ocurren por casualidad, pero prefiero pensar que ésta no es otra cosa que la consecuencia postrera de un trabajo minucioso, concienzudo y con una orientación a objetivos clara.

Así lo entendí como Presidenta de la Sociedad Española de Hospitalización a Domicilio (SEHAD) cuando una agradable tarde de verano de 2017, el doctor Itamar Offer, desde Israel, contactaba conmigo y se mostraba muy interesado por el modelo de Hospitalización a Domicilio vigente en España.

Aquella inicial y agradable conversación telefónica devino con el tiempo en el ambicioso proyecto de organizar el $1^{\circ}$ Congreso Mundial de Hospitalización a Domicilio que tendrá lugar en Madrid los próximos 5 y 6 de abril de 2019.

\section{¿POR QUÉ UN CONGRESO MUNDIAL?}

Desde sus orígenes, a mediados del pasado siglo, en Nueva York la HAD ha conseguido un desarrollo considerable a nivel mundial, tanto en implementación del modelo, unidades, profesionales y recursos, como de funciones desarrolladas; a su origen claramente ligado a la función de alta precoz se han unido su visión a posicionarse como referente experto en diferentes procesos realizados en el domicilio del paciente (TADE) (1,2,3), generar evidencia en diversas líneas estratégicas, así como a mostrarse eficiente en garantizar la continuidad asistencial de los procesos entre atención primaria y hospitalaria, entre otros logros (4).

Con un empuje inicial claramente anglosajón, el modelo se expande y afianza en el ámbito europeo, asiático y latinoamericano.

Sin embargo, y a pesar de la progresión del modelo a nivel mundial, permanecen algunas sombras en aspectos clave: la definición clara del concepto hospitalización a domicilio, su enfoque eficiente a la patología aguda (con claras posibilidades de desarrollo), las múltiples posibilidades que ofrece el cubrir el gap entre atención hospitalaria y primaria, la potenciación de la toma de decisiones que vira a favor de paciente y cuidador, su modelo de financiación, la consideración de "expertos" de sus profesionales en el domicilio, etc.

A nivel nacional, la HAD no está no está al margen de los claroscuros mencionados. Conocedora de los mismos y consciente de su propia responsabilidad, la SEHAD reivindica la hospitalización a domicilio "como modalidad asistencial consolidada y generalizada, que permite dar una atención al paciente digna, equitativa, próxima, ajustada a sus necesidades, segura y excelente. Contribuye a la sostenibilidad del sistema y acerca la atención especializada al escenario terapéutico natural que es el propio domicilio". 
Y lo hace consciente de la evidencia generada a lo largo de los más de 30 años de existencia como alternativa asistencial en España, así como de que algunas de sus características son mencionadas en la literatura que aborda la nueva visión que los hospitales han de adoptar a corto y medio plazo. De los 14 key messages descritos por Rivera y colaboradores en hospital del futuro (5), 8 son asumidos tradicionalmente por la HAD:

- Innovación centrada en el paciente.

- Nuevos roles profesionales.

- Hospital conectado

- Cuidados integrados y equipos orientados a procesos.

- Gobernanza.

- Investigación y educación como resultados clave.

- Organización abierta.

- Nuevos ámbitos de servicio.

La HAD debe ser consciente también de los cambios presentes y venideros de las estrategias sanitarias para así adaptarse y alinearse con las líneas prioritarias que ellas definan.

La reivindicación de tradicionales ventajas de la HAD referidas a aspectos como la satisfacción de paciente y cuidador, deben dejar paso a sus logros en términos de resultados en salud, concreción de modelos de complejidad estandarizados, implementación de guías y protocolos clínicos adecuados al entorno de trabajo y definición de una cartera de servicios que nos distinga de otros recursos asistenciales, sin entrar en competencia con ellos.

En este $1^{\circ}$ Congreso Mundial abordamos cinco áreas preferenciales: definición del concepto de hospital a domicilio, modelos organizativos, ética y legislación en HAD, papel de la tecnología y financiación.

La participación de ponentes con una gran representación de países en este Congreso, unido a una estrategia de "sumar" experiencia, valores y conocimiento, sin duda nos permitirán aportar luz a la hospitalización a domicilio y a ubicarla como modelo sanitario estratégico, tanto actual como de futuro. ¡Subámonos por tanto a la oportunidad que nos brinda este tren!

Nos vemos en Madrid en abril 2019.

\section{BIBLIOGRAFÍA}

1. López Cortés LD, Mujal Martínez A, Fernández Martínez de Mandojana M, Martín N, Gil Bermejo M, Solá Aznar J, et al; Grupo de la Sociedad Española de Enfermedades Infecciosas y Microbiología Clínica (SEIMC), Grupo de la Sociedad Española de Hospitalización a Domicilio (SEHAD). Resumen Ejecutivo del tratamiento antibiótico domiciliario endovenoso: Directrices de la Sociedad Española de Enfermedades Infecciosas y la Sociedad Española de Hospitalización a Domicilio. Hosp Domic. 2018;2(4):165-77. DOI: 10.22585/hospdomic.v2i4.53

2. Ponce González MA, Mirón Rubio M, Mujal Martinez A, Estrada Cuxart O, Fiuza Perez D, Salas Reinoso L, et al. Effectiveness and safety of outpatient parenteral antimicrobial therapy in acute exacerbation of chronic obstructive pulmonary disease. Int J Clin Pract. 2017;71(12):1-9. DOI: 10.1111/ijcp.13022; PMID: 28949430

3. González-Ramallo VJ, Mirón-Rubio M, Mujal A, Estrada O, Forné C, Aragón B, et al. Costs of outpatient parenteral antimicrobial therapy (OPAT) administered by Hospital at Home units 
in Spain. Int J Antimicrob Agents. 2017;50(1):114-8. DOI: 10.1016/j.ijantimicag.2017.02.017; PMID: 28499957

4. Massa Domínguez B. La hospitalización a domicilio en el siglo XXI. Hosp Domic. 2017;1(1):7-9. DOI: 10.22585/hospdomic.v1i1.8

5. Ribera J, Antoja G, Rosenmöller M, Borrás P. Hospital of the future: A new role for leading hospitals in Europe [monografía en Internet]. Barcelona, España: IESE Business School; 2006 [consultada 8 enero 2019]. Disponible en: https://media.iese.edu/research/pdfs/ST-0388-E.pdf 